\title{
Tribunas y panfletos: la primera campaña presidencial del Partido Socialista bajo la ley Saenz Peña ${ }^{1}$
}

Silvana Alejandra Palermo

\section{Resumen}

Este artículo examina la campaña presidencial del Partido Socialista (PS) en 1916 a fin de ponderar el papel transformador de la ley Sáenz Peña en Argentina. Se concentra en el modo en que hombres y mujeres experimentaron la política electoral en una sociedad afectada por las profundas mutaciones acaecidas en la década de 1910, tanto a nivel local como internacional. Desde una perspectiva socio-cultural aborda este caso de estudio, utilizando la información proporcionada por el diario La Vanguardia (LV), órgano oficial de dicho partido.

Palabras clave: Campañas electorales - elecciones - Partido Socialista - Ley Sáenz Peña

\section{Summary}

This article explores the presidential campaign carried out by the Socialist Party (PS) in 1916 to understand the changes brought about by the so-called Sáenz Peña Law in Argentina. It concentrates on how men and women experienced electoral politics in a society shaped by the transformations that characterized the 1910s, both at local and international level. Taking into consideration perspectives from social and cultural history, it examines this case-study based on the information provided by La Vanguardia (LV), the official newspaper of the Socialist Party.

Keywords: Electoral campaigns - elections - Socialist Party - Sáenz Peña Law

\section{Introducción}

La aprobación de la ley electoral de 1912 que estableció la obligatoriedad del sufragio para los varones nativos o naturalizados, el voto secreto y la representación de la minoría en el legislativo marcó un punto de inflexión en la historia política argentina. Esta idea, explícita o implícita en las narrativas sobre la historia nacional, presupone una níti-

\footnotetext{
${ }^{1}$ Trabajo recibido el 01/04/2016. Aceptado el 05/07/2016.

${ }^{2}$ Docente de la Universidad Nacional de General Sarmiento. Investigadora Adjunta del Consejo Nacional de Investigaciones Científicas y Técnicas. Contacto: palermosilvi@gmail.com
} 
da distinción entre la vida política de la denominada república oligárquica y la llamada república democrática. En las últimas décadas, la historiografía ha puesto en duda este presupuesto. Por un lado, algunas investigaciones sobre la política de fines del siglo XIX destacan su carácter dinámico fruto del asociacionismo, la prensa, el diligente ejercicio de las libertades públicas y una vida electoral, caracterizada por un abigarrado calendario y una relativa incertidumbre en los resultados electorales. Por su parte, algunos especialistas de la política argentina de entreguerras tienden a subrayar las continuidades existentes con el pasado más que a destacar las innovaciones de la vida política de comienzos del siglo XX, en términos de prácticas electorales, conceptualización de la representación y funcionamiento partidario. ${ }^{3}$

Hoy el impacto de la ley electoral de 1912 ha dejado de presuponerse. Cabe interrogar, por tanto, hasta qué punto y de qué manera esta nueva normativa electoral afectó las prácticas partidarias. A la vez, conviene replantear esta problemática contemplando enfoques que iluminen sus aristas menos conocidas. Con este propósito, este artículo explora cómo los hombres y las mujeres experimentaron la vida política electoral en una Argentina transformada por los cambios económicos, sociales y culturales que acaecieron durante la década de 1910. Se detiene en la primera campaña presidencial ocurrida bajo la ley Sáenz Peña y selecciona el caso del Partido Socialista (PS), el cual se analiza fundamentalmente sobre la base de la información proporcionada por el diario de dicho partido, La Vanguardia (LV).

El primer lanzamiento del PS a la carrera presidencial no ha merecido una reconstrucción pormenorizada, pese al creciente interés de la literatura histórica tanto por el PS como por las campañas electorales. Junto a la reconsideración de sus orígenes, la historiografía sobre este partido se centra en sus escisiones, su posición en los debates sobre la cuestión social y electoral, las relaciones entre el partido y el movimiento obrero, su accionar en el terreno social y cultural. ${ }^{4}$ Puede que el relativamente modesto desempeño electoral del PS en las primeras décadas del siglo XX haya contribuido a desestimar sus prácticas electorales. De hecho, los pocos estudios dedicados a esta cuestión optaron por aquellos casos en que los resultados comiciales le fueron favorables: el triunfo de

\footnotetext{
${ }^{3}$ Ver Sábato, (1998); Alonso, (2000); Persello, (2004); De Privitellio, (2011).

${ }^{4}$ Camarero y Herrera, (2005); Portantiero, (1999); Walker, (1977); Buonome (2015), Martinez Mazzola (2015); Poy (2015).
} 
Alfredo Palacios en 1904 o las sucesivas elecciones para legisladores nacionales de 1912, 1913 y 1914 -realizadas ya bajo la nueva ley electoralque le aseguraron logros significativos, como una banca en el Senado a Enrique del Valle Iberlucea. ${ }^{5}$ Por lo general, los historiadores analizan las prácticas políticas, las estrategias y los discursos partidarios con el fin de estimar su eficacia electoral. En tal sentido, no sorprende que la literatura se concentre en el gran beneficiario de la ley Sáenz Peña: la Unión Cívica Radical (UCR). ${ }^{6}$

A la luz de esta suscita revisión historiográfica, conviene clarificar el presupuesto central del presente análisis. Este estudio de la campaña presidencial del PS no procura evaluar su desempeño en términos de rédito electoral, aún cuando pondere su capacidad de concitar la atención ciudadana. Como era evidente para los contemporáneos, el PS tenía escasísimas posibilidades de triunfar en la contienda presidencial de 1916. Aquí, la campaña representa un punto de mira apropiado para dilucidar el modo en que dirigentes partidarios, militantes, simpatizantes y también hombres y mujeres sin afiliación partidaria vivieron y dieron sentido a la política electoral en el marco de las nuevas reglas establecidas por la ley de 1912. En tal sentido, sostenemos que si bien la nueva ley electoral implicó de por sí una transformación en las prácticas políticas, la magnitud, el sentido de ese cambio no puede deducirse simplemente en función de sus alcances normativos sino que exige explorar los usos que la sociedad hizo de ella. Y como se espera demostrar con esta reconstrucción de la campaña presidencial del PS, ese uso fue intenso. Durante casi tres meses consecutivos, la cotidianeidad de grandes y pequeñas localidades del país se vio alterada por una hervidero de tribunas, panfletos y deberíamos agregar afiches, cuya proliferación daba cuenta del estrecho vínculo que la sociedad establecía con la política electoral.

\section{Redoblar la propaganda: el PS en la carrera presidencial}

Para el PS, que había nacido en 1894 y acuñado, en cierta medida, una activa vida partidaria, la ley de 1912 representó, sin embargo, un desafío sin precedentes. En febrero de ese año, tras aprobarse la reforma electoral, LV sostenía:

\footnotetext{
5 Torre, (1973); Gaurguin, (1999).

${ }^{6}$ Karush, (2002); Horowitz, (2015); Valdez (2012); Alemán (2014).
} 
«En general, todos los partidos toman la reforma como un ensayo, cuyas consecuencias no pueden preverse sino en parte mínima. El voto obligatorio, sobre todo, que acaso constituya la característica principal de la nueva ley, es un salto a lo desconocido, que puede dejarnos mal parados. ¿Aumentará con él la masa aplastadora de la inconsciencia y la venalidad? ¿Ganará para la vida cívica fuerzas sanas, hoy sumidas en la indiferencia?

De todos modos, el nuevo régimen impone al Partido Socialista un redoblamiento de actividad, y acaso una visión más amplia de la lucha y un conocimiento más exacto del campo en que ha de librarse» ${ }^{7}$

Al llegar los comicios del domingo 2 de abril de 1916, en los que se elegían delegados al colegio electoral responsable del nombramiento de la fórmula de presidente y vicepresidente de la nación, el PS tenía una estructura organizativa que podía movilizar para la campaña. Es verdad que, si bien funcionaban sedes partidarias en las principales ciudades del país, su inserción era más abigarrada en la capital de la república. A diferencia de la UCR, la cual en los años previos a la aprobación de la Ley Sáenz Peña optó, en términos generales, por la abstención electoral, el PS había participado en las elecciones desde su fundación. Posiblemente, esto le brindaba cierta confianza a la hora de la movilización electoral. No obstante, los comicios de abril de 1916 constituían un reto de mayores proporciones.

¿En qué consistió, entonces, ese «redoblamiento de la actividad»? En julio de 1915, el PS tomó la decisión de participar en las elecciones presidenciales en su Segundo Congreso Extraordinario. La formula quedó integrada por Juan B. Justo como presidente y Nicolás Repetto para vice-presidente. A partir de entonces no se escatimaron energías para lo que resultó ser una campaña tan interesante como agotadora. Los comicios del 2 de abril transcurrieron con normalidad y atrajeron a casi el $63 \%$ de los registrados en el padrón, esto es 745.852 votantes. No provocó sorpresa que la mayoría -más de 340.000- se inclinara por la UCR y que el PS obtuviera el apoyo de aproximadamente 66.300 votantes. Sí desilusionó a los socialistas la derrota en la contienda por diputados de la capital, en la que alcanzaron las tres posiciones de la minoría ante los ocho representantes logrados por el radicalismo. Estos resultados, sin embargo, no reflejaban adecuadamente las simpatías de la ciudad de Buenos Aires. La escisión de A. Palacios del PS y la consecuente forma-

${ }^{7} L V, \mathrm{~N}^{\circ} 1808,9$ de febrero de 1912, en Reinoso (1985):72. El destacado es nuestro. 
ción del Partido Socialista Argentino (PSA) hizo que éste se presentara por separado en la elección. Por tanto, si se suman los votos de ambas fracciones socialistas en la Capital Federal, éstos representan un 60.2\% del total respecto al $47,1 \%$ obtenido por el Radicalismo. ${ }^{8}$

El PS encontró en la palabra el instrumento privilegiado para concitar la atención ciudadana. La propaganda oral se realizó a través de eventos de lo más variados y en ámbitos de lo más diversos. Las conferencias, una práctica habitual en la vida partidaria, representaron una de esas variantes. Por lo general, estas acontecían en espacios cerrados: teatros, salones, sedes partidarias o centros asociativos. Incluían una disertación como componente central, acompañada de alguna otra actividad acotada: el recitado de una poesía o la entonación de himnos a los trabajadores a cargo de un coro. En el marco de la campaña, la necesidad de multiplicar estos eventos hizo que, inclusive los bares, sirvieran de escenarios propicios. Así, para recibir a un candidato del PS en gira de propaganda por Córdoba, se organizó un acto en el «bar San Martín» de San Francisco. Tras escuchar a una orquesta de «obreros simpatizantes», el visitante discurrió sobre la posición del socialismo ante la religión, la familia, la educación, la explotación del trabajo y el drama de la guerra europea. El auditorio lo premió con «entusiastas aplausos.» El balance se juzgo positivo: por primera vez se había realizado un acto socialista en esa localidad y la «conferencia» había contado con más de doscientas personas. ${ }^{9}$

Aunque las conferencias atrajesen un público amplio, las limitaciones de espacio y el hecho de que requirieran de la decisión de asistir quizás limitaran la participación. Su importancia, de todos modos, no puede desestimarse. La competencia electoral obligaba a afianzar lealtades y entusiasmar inclusive a aquellos seguidores más fieles. Con este mismo fin, se celebraban también actos más bien festivos. Las fiestas campestres, organizadas en muchos casos por los comités electorales, aprovechaban el deleite del tiempo libre para fortalecer los vínculos entre afiliados y personas afines al partido. Por ejemplo, el comité electoral de las secciones 5 y 16 de la capital federal invitó a una fiesta dominguera, en el Tiro Suizo en el barrio de Belgrano. El programa incluía: banda de música, juegos de tiro al blanco y baile familiar. El recordatorio sobre el uso obligatorio de la insignia partidaria constituía el síntoma más evi-

\footnotetext{
${ }^{8}$ Walker, (1977): 138.

${ }^{9} L V, 13 / 03 / 1916$, p. 4.
} 
dente de que estas fiestas apuntaban a reafirmar y visibilizar esa identificación. ${ }^{10}$

Claro que en contiendas electorales bajo un sistema con voto secreto y obligatorio, era imprescindible alcanzar un público amplio, persuadir a los indecisos y de ser posible a quienes cobijaran otras preferencias partidarias. Para esto, el instrumento más apto pareció ser el mitin, que consistía en una tribuna colocada en un espacio público, desde la cual dirigían la palabra uno o varios oradores. La concurrida esquina de un barrio, una plaza o los alrededores de un centro fabril constituían escenarios apropiados. Así, por ejemplo, una noche, en la plaza Solís del barrio de la Boca, tuvo lugar un acto al que asistieron alrededor de mil doscientas personas. Hablaron tres oradores, entre ellos Augusto Bunge quien discurrió sobre la plataforma electoral, la enseñanza primaria y la necesidad del sufragio universal municipal. ${ }^{11}$ Conferencias y mitines eran la excusa perfecta para poner en contacto a la población con los candidatos, darle la posibilidad de escucharlos y conocerlos personalmente. Esto obligaba a los candidatos a realizar giras por todo el país. En algunos casos, viajaban para apoyar la proclamación de los diputados provinciales, como lo hizo J. B. Justo al visitar Rosario el último domingo del mes de enero. ${ }^{12}$ Como estas giras se hacían por ferrocarril, la parada del tren brindaba la oportunidad de celebrar un pequeño acto. Estos encuentros insumían preparativos cuidadosos por parte de los militantes de esas pequeñas localidades, quienes los juzgaban acontecimientos de envergadura, pese a su fugacidad.

Lógicamente, los actos al aire libre -denominados alternativamente mitines, asambleas o conferencias- apuntaban a una audiencia nutrida. No siempre se ofrecían estimaciones del número de asistentes, pero, en ocasiones, se distinguía su perfil. Así por ejemplo, la noticia sobre una «conferencia» organizada en una esquina de la ciudad de San Juan, un sábado a la noche del mes de enero, celebraba que el numeroso público estuviera «compuesto en su mayoría por genuinos obreros.» La crónica encomiaba asimismo la presencia de mujeres, quienes, al parecer, habían empezado a comprender que «ellas debían ocupar un puesto en el ejercito de la democracia obrera.» ${ }^{13}$ Es interesante que, en no pocas oca-

\footnotetext{
${ }^{10} \mathrm{LV}, 21 / 01 / 1916$.

${ }^{11} L V, 03 / 02 / 1916$, p. 2.

${ }^{12} \mathrm{LV}, 23 / 01 / 1916$.

${ }^{13} L V, 23 / 01 / 1916$, p. 2.
} 
siones, los socialistas aludieran al mitin como conferencia. Hasta cierto punto, desde su perspectiva, aquel era una conferencia al aire libre. El alma del mitin, como el de la conferencia, consistía en el discurso de uno o varios oradores. Dada la centralidad del orador y su capacidad retórica, el PS no lo abandonaba a la improvisación. En la convicción de pertenecer a un partido de ideas, las dirigencias socialistas recomendaban que la prédica de campaña se centrara en el programa partidario así como en los logros y proyectos de los legisladores socialistas.

Si las palabras para definir los actos se usaban indistintamente o si, en cierto modo, los términos -conferencia, mitin- eran laxos y referían a situaciones diversas, puede que esto también obedeciera a que, en un clima de elecciones competitivas, estos actos eran maleables. De hecho, el mitin y la conferencia comenzaron a combinarse con la manifestación o el desfile. A diferencia de las conferencias celebradas en lugares cerrados, estos eventos exigían planificar el recorrido a realizar, además de la invitación a los oradores, la música y actos alusivos. Por ejemplo, el jueves 3 de febrero a las 20:30 horas se organizó en el Salón Tipográfico Bonaerense -San Juan al 3200- una conferencia, en la que Juan B Justo ofició como orador. Con tres días de antelación, se informó que los asistentes recorrerían en manifestación la calle San Juan hasta Saavedra al 100, donde se encontraba el «Centro de Cultura B. Rivadavia.» ${ }^{14}$

Esta combinación de conferencia o mitin con un desfile se afianzó a medida que avanzaba la campaña. Así, junto a las sedes partidarias, los centros socialistas, los teatros y asociaciones, las calles se convirtieron en otro espacio fundamental para la política. Y así, a la celebridad de los oradores se sumaba la espectacularidad de los desfiles. En la práctica, esta asociación entre la conferencia o el mitin con el desfile abrió paso al entretenimiento y la diversión: llevar pancartas, cantar más libremente, hacer ruido e inclusive tirar cohetes.

\section{Los grandes «mitines»: la proclamación de candidatos y el cierre de campaña}

El acto de proclamación de la fórmula presidencial constituyó uno de los actos más sobresalientes y más cuidadosamente planificado. Se celebró a casi un mes del escrutinio, el jueves 2 de marzo por la noche, en

\footnotetext{
${ }^{14} \mathrm{LV}, 01 / 02 / 1916$.
} 
la calle Rivadavia, entre Riobamba y Andes (actual Presidente José E. Uriburu). En este trayecto de cuatro cuadras se ubicaron ocho tribunas, en cada una de las cuales disertaron de tres a cuatro oradores: el presentador del acto, un segundo orador (generalmente el principal) y un tercer y, a veces, un cuarto disertante, responsables del cierre. Si bien se anunció que los discursos comenzarían a las nueve y media de la noche, el acto se inició un par de horas antes. Desde las siete y media de la noche, bandas de música y coros del Partido reunidos en el lugar, ejecutaron marchas sinfónicas y entonaron himnos obreros. ${ }^{15}$ Las noticias del acto publicadas al día siguiente por LV, derrochaban optimismo. El titular se refería al «gran mitin de anoche» y la nota celebraba que, pese al descenso de la temperatura y las probabilidades de lluvias, la asistencia hubiera rondado en 50.000 personas. ${ }^{16}$ Para no dejar dudas, LV acompañó su titular con una fotografía de una muchedumbre de hombres reunidos frente a una de las tribunas. De la misma manera, la revista Caras y Caretas publicó fotos de los simpatizantes escuchando a los oradores para documentar la relevancia del acto. ${ }^{17}$

A las nueve y media, el ruido de la bocina emitida desde el local del comité ejecutivo dio inicio al acto, que se prolongó hasta las doce de la noche. Según LV, el acto consistió fundamentalmente en los discursos pronunciados desde las tribunas. Entre los oradores se encontró naturalmente Juan B. Justo (no así el candidato a vicepresidente que se encontraba de gira en el Chaco), los candidatos a diputados nacionales por la capital Enrique Dickmann, Basilio Vidal, José F. Penelón, Augusto Bunge, Fernando de Andreis, José M. Lemos e importantes legisladores como el diputado Mario Bravo y el senador E. Del Valle Iberlucea.

Las tribunas de este acto estaban pensadas para el lucimiento de la oratoria masculina. Era lógico, la política formal estaba reservada a los hombres. La ciudadanía se había ligado al cumplimiento de la defensa militar de la nación y eran sólo los hombres adultos quienes encarnaban las virtudes del buen ciudadano: moderación, cultura y cálculo meditado. Pero las libertades públicas no constituían una prerrogativa masculina. Una mujer podía tomar la tribuna. Y esto fue lo que sucedió en el acto de proclamación de los candidatos del PS. Sin haber sido anunciada y sin que mediara explicación alguna sobre su presencia, Juana M. Begino

\footnotetext{
${ }^{15}$ La Nación, 02/03/1916, p. 10

${ }^{16} L V, 03 / 03 / 1916$, p. 1.

${ }^{17}$ Caras y Caretas, 11/03/1916, p.61.
} 
irrumpió en la cuarta tribuna, la misma que ocupara el candidato presidencial. Desconocemos los motivos de esta alteración en el programa. En cualquier caso, este episodio ilumina las limitaciones, tensiones y alcances de la participación femenina en el PS, un partido que, a los ojos de muchos hombres y mujeres, debía comprometerse con los derechos de la mujer de la misma manera que lo hacía con la causa de los trabajadores. Este fue precisamente el eje de la alocución de J. Begino, quien se mostró poco dada a las sutilezas. Se presentó afirmando: «hablo en nombre de mi sexo, de mi sexo tan acerbamente excluido de los trascendentales problemas de la vida, por el egoísmo varonil». Reclamó para el PS la labor de transformar el código civil, que «nos envilece», y de pugnar por la aprobación de una ley de divorcio absoluto. En los tramos finales de su discurso, además de condenar la guerra europea y augurar un triunfo partidario en los comicios de abril, insistió en que debían ser los diputados socialistas a quienes les «quepa la gloria de haber sido los primeros en ocuparse de la elevación de la mujer». ${ }^{18}$

Esta inesperada participación femenina no constituyó la única variación de un programa, tan puntillosamente planificado. El candidato Basilio Vidal también se apartó, deliberadamente, del libreto preestablecido. Era de rigor que los disertantes del PS centraran sus exposiciones en la descripción de la plataforma partidaria, tratándose de un partido que se reclamaba defensor de ideas y no de liderazgos personales. Sin embargo, Vidal prefirió, según dijo, transgredir una práctica política que puede considerársela como una tradición en nuestras filas para permitirse en esta oportunidad, ocuparme de mi mismo. Y relató su vida. Había nacido en Azul hacía 27 años atrás y estudiado sólo hasta cuarto grado. Desde los quince años había trabajado en el comercio mayorista de Buenos Aires y a los diecisiete años había ingresado al PS. Con emotividad confesó: «al partido le debo lo que soy. El PS ha sido para mí el hogar, el taller y la escuela». Y con idéntica franqueza afirmó al concluir su discurso: «en la relatividad de mis modestas dotes prometo servir al pueblo con la integridad de mi conciencia socialista». A diferencia de las reflexivas intervenciones de muchos de sus compañeros de tribuna, la suya fue una confesión sentida e íntima. En suma, el discurso de Vidal y la presencia de Begino documentan que, más allá de las normas y costumbres del partido, el acto de proclamación de candidaturas dejó margen para la

${ }^{18} L V, 03 / 03 / 1916$, p. 2. 
improvisación. No todos los disertantes hablaron un tono monocorde y una de las voces, que se hizo escuchar, fue de una mujer.

Este predominio de la persona por sobre el programa difícilmente sea atribuible sólo a la singularidad de estas figuras. Esto parece haber obedecido a la lógica de la política electoral, al modo adoptado por la representación en tiempos en que la política se tornaba competitiva y devenía, en cierto sentido, un espectáculo. Este sistema exigía, por cierto, la disputa de ideas, el contrapunto de propuestas, pero a la vez situaba en primer plano a las personas. Y eran éstas las que, en última instancia, debían resultarle, sino familiares, al menos mínimamente conocidas al elector. Es revelador, en tal sentido, que en la mañana del acto de proclamación, LV dedicara su primera página completa a la publicación de los retratos de los candidatos del partido (una página que devino afiche partidario para ser exhibido en el espacio público) y que destinara alrededor de tres columnas de su tercera página, a lo que denominó «apuntes biográficos» de nuestros candidatos.

¿Cómo vivenciaron este acontecimiento esos asistentes, hombres o mujeres, que se reunieron aquella noche de marzo en el centro de la capital? Es difícil saberlo. Pero puede afirmarse que para la mayoría de estos oradores, ese acto de proclamación de candidaturas tuvo mucho de extraordinario. A los ojos de estos dirigentes, muchos de ellos ya experimentados y otros, en cambio, jóvenes recién iniciados a la vida partidaria, la sorpresa se encontraba en la masividad del acto. «Esta imponente asamblea -expresó Augusto Bunge- imponente por el número y por la unidad de su inspiración, evidencia cuán grande es la responsabilidad que implica un mandato legislativo socialista». ${ }^{19}$ De la misma manera, el candidato Francisco Cúneo recalcó «es muy significativo el hecho de tener que recurrir a la vía pública para hacer la proclamación de nuestros candidatos, debido a la falta de locales con capacidad para contener los millares de hombres que con su presencia quieren significar el propósito decidido de hacer triunfar en los comicios del 2 de abril a los candidatos que hemos designado para presidente y vice de la república y para diputados nacionales» ${ }^{20}$

Tras la proclamación de las candidaturas, estas expresiones de civismo se multiplicaron en todo el país. En sus esfuerzos por redoblar la propaganda en la carrera presidencial, el PS encontró a una sociedad

\footnotetext{
${ }^{19} L V, 03 / 03 / 1916$.

${ }^{20} L V, 03 / 03 / 1916$, p. 2.
} 
receptiva, curiosa, intrigada por la novedad del acontecimiento. Marzo fue un mes agitadísimo. Y las innovaciones tecnológicas acompañaron a los socialistas sólo a medias o, lo que es peor aún, le hicieron su labor más agotadora. Por un lado, la densidad de la red ferroviaria de la Argentina les permitía visitar numerosas localidades en corto tiempo. Por otro, dada la carencia de un sistema de amplificación del sonido, los oradores debían apelar a sus propias capacidades vocales y gestuales para hacerse escuchar y mantener la atención del público. En tal sentido, tras detallar el cronograma de la gira de propaganda a realizarse entre el 13 al 21 de enero en la provincia de Buenos Aires, el secretario general del partido Sr. Carlos Pascali sumaba una nota reveladora. Le recomendaba a los secretarios de los centros socialistas de dicha provincia que «activen la organización de esos actos de propaganda y procuren que en lo posible se realicen en locales cerrados, por el enorme esfuerzo que implica a los propagandistas tener que hablar al aire libre». ${ }^{21}$ La campaña presidencial demandó un esfuerzo inesperado. Y en éste los oradores constituían una pieza fundamental e irremplazable, tanto que la palabra «propagandista» adquiría una connotación positiva y enaltecedora.

En el marco de una campaña con un creciente número de personas involucradas en los eventos partidarios, los actos públicos se tornaban más despojados o, al menos, más ruidosos. El historiador Peter Fritzsche ha señalado que algunas campañas electorales de la Alemania de la República de Weimar merecen considerarse como verdaderas fiestas populares. ${ }^{22}$ Con las reservas del caso, puede que esto también fuera, o comenzaba a ser así, en la Argentina de mediados de la década de 1910, al menos si confiamos en la descripción realizada por LV sobre el acto del cierre de campaña del partido. El hecho de que le dedicara toda la primera página (algo que no sucedió con la proclamación de las candidaturas), la importante foto de una numerosa columna y los rimbombantes titulares que calificaban al acto como una «apoteosis de la democracia socialista», un «desfile colosal», apuntaban a transmitir, inclusive al lector más desprevenido, la grandiosidad del evento.

En efecto, para su cierre de campaña, el PS organizó un acto, al que definió como un mitin, el viernes 31 de marzo en la ciudad de Buenos Aires. En realidad, no fue uno sino varios coronados por un desfile. En los distintos barrios de la capital se organizaron mitines y desde allí,

${ }^{21} L V, 12 / 03 / 1916$, p. 4.

${ }^{22}$ Fritzsche, (1990). 
las columnas de manifestantes -siete en total- se dirigieron a la plaza San Martín para dar cierre al acto a las nueve de la noche. El evento requirió de una planificación cuidadosa destinada a movilizar el mayor número de asistentes. El público respondió a la convocatoria. Según se informó la calle Rivadavia, entre Once y la Plaza Congreso, se colmó de una concurrencia entusiasta mucho antes del arribo de las columnas. A lo largo del trayecto, numeroso público expresó su simpatía desde los balcones de las casas con aplausos y vivas al paso de los manifestantes. $\mathrm{Al}$ parecer, en el momento de mayor despliegue, las columnas ocupaban alrededor de 40 cuadras de la ciudad. También la revista Caras y Caretas le dedicó una foto con un epígrafe que estimaba un total de asistentes de alrededor de treinta a cuarenta mil personas. Por su parte, el diario La Nación, calificó este cierre como uno de los actos «más numerosos que se hayan realizado en la actual campaña electoral.» ${ }^{23}$

Entre los oradores figuraron naturalmente Juan B. Justo y N. Repetto. El senador Del Valle Iberlucea habló en dos oportunidades, al iniciarse la concentración en la plaza Lavalle y luego en la plaza San Martín. Como lo había hecho al narrar el acto de proclamación de candidaturas, la crónica de LV se enfocó en el discurso de los candidatos, importantes (aunque no únicos) protagonistas de la jornada. En efecto, no pudo evitar detenerse en otros detalles y actores no menos relevantes. En su afán por no dejar dudas sobre la honorabilidad de la clase obrera, el PS apostaba a que el mitin fuera una «grandiosa ostentación de fuerza y cultura». Por tanto, recomendaba que se marchara ordenadamente y que no se permitiera la actuación de ningún «elemento perturbador». ${ }^{24} \mathrm{La}$ realidad no se ajustó a estas prescripciones. LV reconoció que "llamó la atención y fueron muy festejados los carteles humorísticos dedicados a los radicales y causaron hilaridad las canciones picarescas dedicadas también a los mismos». ${ }^{25}$ Nada de esto parecía perturbador pero no pudo negarse que otras «figuras alegóricas» resultaron conflictivas. La columna de la $19^{a}$ portó, a modo de estandarte, «un burro escuálido sobre el cual cabalgaba un radical con boina blanca, tratando de darle un pan bazo que colgaba de una caña.» Se informó que su cabalgata por la Avenida Rivadavia desató las risas de todos los asistentes a punto tal de que, al llegar a la calle Ayacucho, la policía considero pru-

\footnotetext{
${ }^{23}$ Caras y Caretas, 08/04/1916, p. 55; La Nación 01/04/1916, p.9

${ }^{24} L V, 31 / 03 / 1916$, p. 1.

${ }^{25} L V$, ol/04/1916, p. 1.
} 
dente intervenir temiendo que los radicales respondieran a esta ofensa con violencia. Pero, según informó $\mathrm{LV}$, «los de la $19^{a}$ querían tanto a su burro que fueron necesarias largas gestiones de los diputados Bravo y de Tomaso sobre la conveniencia de acceder al pedido». Finalmente, el comisario y sus agentes transportaron al burro al local del comité ejecutivo. ${ }^{26}$

\section{La prensa, los folletos y los afiches}

En esta campaña, la propaganda oral estuvo acompañada por la propaganda escrita (y visual): ambas se complementaron y reforzaron mutualmente. Hemos dicho que la prensa socialista publicitaba fechas, horarios, lugares y características de todos los actos partidarios. En ocasiones, también se utilizaban carteles para difundir información sobre mitines y conferencias. A su turno, estos actos constituían una excelente ocasión para la distribución de panfletos y volantes. Así, por ejemplo, el día de la proclamación de las candidaturas, se solicitó a los secretarios electorales que retiraran del Comité Central el manifiesto del grupo parlamentario para ser distribuido en el acto. ${ }^{27}$

Esta estrecha complementariedad entre actos públicos y propaganda escrita no sorprende a la luz del alto grado de alfabetización alcanzado por entonces por la sociedad local, en comparación con otras naciones latinoamericanas. Los folletos requerían de ciertas capacidades para la lectura sostenida y la comprensión. La campaña había dado excusa para la publicación de pequeñas obras, a las que se denominaba «panfletos», firmados por sus autores, como el titulado «Regeneradores? No; mistificadores!» escrito por el Sr. Ernesto Muella, en «prosa recia, dura, apasionada» dedicado a «combatir los hombres y las cosas del partido radical». ${ }^{28}$

Como era de esperarse, el diario $L V$ dedicó una atenta cobertura a todo lo relacionado a la campaña electoral. Y, en tal sentido, la prensa del partido representó una herramienta fundamental de propaganda. Pero, como han reconocido los estudiosos de este periódico, $L V$ se pretendía un periódico moderno, capaz de informar sobre una diversidad de temas

\footnotetext{
${ }^{26} L V, 01 / 04 / 1916$, p. 2.

${ }^{27} \mathrm{LV}, 03 / 03 / 1916$, p.5.

${ }^{28} L V, 03 / 03 / 1916$, p. 6.
} 
con cierta objetividad y no simplemente un instrumento del PS. ${ }^{29}$ En consecuencia, no se puso enteramente al servicio de la propaganda. Las noticias nacionales -sobre política parlamentaria, el movimiento obrero, entre otras- y las internacionales, en especial el devenir de la guerra europea, no se vieron menoscabadas por la campaña electoral y lo mismo aconteció con las secciones especiales, que se publicaron con regularidad. Sólo recién al final de la campaña, $L V$ advirtió que las secciones de doctrina socialista, ciencia y educación que debían publicarse el martes 28 de marzo se dejarían para el viernes siguiente, a causa de las «necesidades de la propaganda electoral». ${ }^{30}$

No obstante, $L V$ experimentó algunos cambios, aunque no del todo drásticos, desde mediados de marzo. Al avanzar la campaña, debió publicar regularmente la nómina de los candidatos a electores de presidente y vice, a diputados nacionales así como las direcciones de todas las secciones electorales de la capital y especificó también la ubicación de los domicilios particulares y locales donde se podía obtener gratuitamente folletos de propaganda y boletas de voto. ${ }^{31}$ Asimismo, el diario comenzó a incluir unos pequeños recuadros con frases cortas, penetrantes, una suerte de lemas o slogans de campaña, aunque un tanto más largos. La mayoría de estos recuadros tenían una forma similar, con las iniciales del partido entrelazadas en un costado, el tipo de letra del mensaje era más grande y al estar bien enmarcados eran fácilmente distinguibles. Estos mismos mensajes encuadrados se imprimían en gran cantidad y eran pegados en los espacios públicos para concitar la atención del electorado. Se los denominaba fajas. $L V$ publicó varios de ellos entre el lunes 20 de marzo y el día de los comicios, a un promedio de dos por día. En su mayoría transmitían un mensaje directo y claro, apelando a sus interlocutores específicos. Sus encabezados consignaban: «Futuros soldados», «Trabajadores» ${ }^{32}$ o parodiando inclusive el pensamiento de un elector arrepentido, uno de ellos se iniciaba con la frase «He votado mal» y resumía las cavilaciones de un votante que tras comparar la acción parlamentaria del PS con la del partido de su anterior elección, terminaba afirmando que, en los comicios del 2 de abril: «votaré por los candidatos socialistas». ${ }^{33}$ Algunos reclamaban la asistencia de los militantes, sobre

\footnotetext{
${ }^{29}$ Gené y Buonome, (2013).

${ }^{30} L V, 28 / 03 / 1916$, p. 2.

${ }^{31}$ Cf. por ejemplo, $L V, 13 / 03 / 1916$, p. 5.

${ }^{32} L V, 21 / 03 / 1916$ y 23/03/1916, p2. .
} 
todo en los tramos finales de la campaña. Raramente el mensaje de estos recuadros marcaba un fuerte contraste entre el PS y otros partidos. Uno de ellos sí consignó que los «socialistas no engañan» mientras «los otros partidos mienten». ${ }^{34}$ Sin embargo, el mensaje de esta faja podría considerarse la excepción a la regla.

El diario $L V$ también publicó una suerte de afiches, tres en total, ironizando sobre la UCR. ${ }^{35}$ A diferencia de las fajas, destinadas a insistir de manera clara, contundente y en ocasiones en forma pegadiza, sobre las virtudes y nobles luchas del PS, estos afiches, apelaban al humor para desprestigiar al opositor a los ojos de los electores. Uno de ellos representaba a un sacerdote, parecido a $\mathrm{H}$. Yrigoyen, con un texto que aclaraba: «Defendemos el culto católico porque nos da votos! Honramos la bandera porque cubre nuestra mercancía Amamos la patria porque nos engorda!» Sabemos que uno de estos afiches se utilizó en la propaganda callejera, pues se invitó a los secretarios de las secciones a pasar por la secretaria general a buscar el póster titulado «No te aflijas, Vicente», disponible para ser pegado a partir del 20 de marzo. ${ }^{36}$ Aquí figuraba $\mathrm{H}$. Yrigoyen rezando y Vicente Gallo, cual pájaro expectante posado en un poste de alambrado. El tercero de ellos aludió a lo que el PS denunciaba como un nacionalismo superfluo. Un correligionario se preparaba para hacer propaganda electoral mientras conversaba con el radical José C. Crotto, quien se desempeñara como senador por la Ciudad de Buenos Aires entre 1912 y 1918. Este último le indicaba que preparara «los chirimbolos patrióticos» porque, como la UCR ya tenía fórmula presidencial, H. Yrigoyen quería que se hablara mucho de la patria. Estos pósters compartían algunos de los rasgos de la propaganda política de otras partes del mundo. Por ejemplo, en la Gran Bretaña de comienzos de siglo XX, los pósters políticos estaban más influenciados por la tradición de la caricatura que por la naciente industria de la publicidad y solían combinar la imagen con un texto, para nada menor, destinado a reforzar el sentido del mensaje y despejar cualquier ambigüedad. ${ }^{37}$

En una campaña electoral, la atracción de los afiches no radicaba sólo en su diseño y mensaje sino también en las disputas que se entabla-

\footnotetext{
${ }^{33} L V, 23 / 03 / 1916$, p. 3

${ }^{34} L V, 24 / 03 / 1916$, p. 3.

${ }^{35}$ Las tres fueron publicadas el viernes $31 / 03 / 1916$, p. 5, 6, 7 .

${ }^{36} L V, 20 / 03 / 1916$, p. 2.

37 Thompson, (2007).
} 
ban para exhibirlos. Al respecto, es interesante que $L V$ informara que, en la capital, los partidos políticos habían denunciado el destrozo sistemático de los carteles a la policía y, por tanto, la jefatura había recomendado a las comisarías que el personal de calle intentara evitar que se arrancaran o cubrieran los carteles de las agrupaciones, por parte de quienes oponiéndose, buscaban pegar los propios o simplemente destruir la propaganda de sus contrincantes. ${ }^{38}$ Pero, al parecer, las autoridades no eran imparciales. La animosidad que exhibían para con los militantes socialistas fue denunciada, como lo revelaba el hecho de que diferentes comisarios de la capital impedían fijar afiches de propaganda del PS en sus barrios. ${ }^{39}$

Como sostiene Jon Lawrence, estas contiendas incrementaban los costos de la política tanto en términos del trabajo invertido en la pegatina como respecto a los montos necesarios para financiar una inacabable cantidad de carteles. En tal sentido, este historiador argumenta que en la Gran Bretaña de principios del siglo XX, el impacto de los pósters de gran formato debe ponderarse cuidadosamente. Además de los costos, este tipo de propaganda encontró límites en las regiones rurales, donde no había tantos lugares para exhibir afiches y, en su opinión, ni el panfleto ni el afiche pudieron superar la efectividad de la voz humana. ${ }^{40}$ Por cierto, el problema de los costos no era un dato menor para el PS en Argentina. Este reconocía que contaba con recursos limitados para la propaganda escrita, lo cual lo obligaba a confiar en la propaganda de las tribunas. De todos modos, aún teniendo en cuenta estas restricciones, para los socialistas, los folletos y los afiches y, en cierta medida el diario $\mathrm{LV}$, se convirtieron, como se ha visto, en herramientas útiles a la hora de emprender esta novedosa campaña electoral.

\section{Palabras finales}

Con este examen de la campaña del PS en la elección presidencial de 1916 procuramos aproximarnos a la experiencia de la sociedad con la política electoral en tiempos en que la competencia partidaria se profun-

\footnotetext{
${ }^{38} L V, 19 / 03 / 1916$, p. 2.

${ }^{39} \mathrm{LV}, 27 / 03 / 1916,4$.

${ }^{40}$ Lawrence, (2006) y (2009).
} 
diza, al implementarse la ley de 1912. Creemos haber documentado el indiscutible compromiso del PS con esta empresa y el intenso esfuerzo que le demandó. En cierta medida, esto obedeció a que, a diferencia de otras campañas de su historia como la que convirtió a A. Palacios en legislador, esta campaña logró un alcance nacional. En ella se destacó la propaganda basada en la palabra y la presencia de los representantes partidarios, canalizada en una diversidad de actos, entre los que sobresale el mitín, dotado a mediados de esta década de una fisonomía polifacética. En una sociedad que aún no contaba con la radio, las tribunas eran claves para poner en contacto al candidato con sus eventuales votantes. Si la oratoria del conferenciante constituía un ingrediente central para el éxito del acto, la capacidad de escucha de los asistentes no era un dato menor. Claro que, como se ha visto, existió una estrecha complementariedad entre propaganda oral y escrita. En una sociedad relativamente alfabetizada y dado que se trataba de un partido fuertemente identificado con la cultura letrada, el papel de la propaganda escrita, igualmente rica y diversa, no puede soslayarse, aún sin desestimar el peso de las limitaciones de recursos que constreñían la acción partidaria en tal sentido.

Otro hallazgo de esta indagación, aún provisional, radica en haber detectado la distancia que medió entre las prescripciones esgrimidas por el PS y las prácticas que surgían al calor de la competencia electoral. No todo lo que el PS hizo durante la campaña se correspondió con lo que proclamaba. Más allá de la intencionalidad de los actores involucrados, la campaña adquirió una lógica propia y su dinámica puede haber redefinido la racionalidad de los protagonistas. El PS quería ser, y en cierto sentido lo era, un partido de ideas, no de liderazgos individuales; un partido de propuestas sólidas, no de una simple retórica crítica; un partido de prácticas respetuosas, no de acciones descalificadoras. Sin embargo, al fragor de la campaña, se hizo evidente que junto a los principios, también interesaban las personas; junto a la enunciación de las propuestas propias se condenaban las ajenas; y el tono digno daba paso a un humor sarcástico, a la parodia nada sutil sobre el oponente político.

Por último, hemos intentado ponderar algunas de las transformaciones de las prácticas políticas en la década de 1910. Como se ha insistido, la ley electoral de 1912 contribuyó en tal sentido, pero no alcanza a explicarlas. Si la ley resultó fuertemente transformadora, esto obedeció a la existencia de una sociedad dispuesta a ensayar sus novedades. La propia decisión del PS de participar en las elecciones presidenciales, aún 
con escasas probabilidades de éxito, resulta reveladora al respecto, como también lo fueron esos tres intensos meses de campaña. Para quienes se habían formado en la política de fines del siglo XIX, esta era, sin duda, una experiencia transformadora. No sorprende que en el acto de proclamación de las candidaturas, Juan B. Justo manifestara con elocuencia:

«Es tan grande la vitalidad de nuestro partido y tan rápido su desarrollo, que aun viejos propagandistas como yo debemos en cada campaña electoral adaptarnos a situaciones nuevas. Estaba acostumbrado a hablar en locales cerrados, y ahora con frecuencia veome ante asambleas que por su magnitud solo pueden celebrarse al aire libre, y después de ser por décadas candidato a diputado sin perspectivas de éxito electoral, veome ahora aclamado como candidato a la presidencia de la república» $»^{41}$.

\section{Bibliografía}

ALEMAN, Marianne González, (2014), «Ciudadanos en la calle. Violencia, virilidad y civilidad política en la campaña presidencial porteña de 1928.» Hispanic American Historical Review 94.3: 421-453.

ALONSO, Paula, (2000), Entre la Revolución y las urnas. Los origenes de la Unión Cívica Radical y la politica argentina en los años '90. Buenos Aires: Sudamericana.

BUONOME, Juan, (2015), «Fisonomía de un semanario socialista: La Vanguardia, 1894-1905», Archivos de historia del movimiento obvero y la izquierda, Año IIII, n. 6: 11-30.

CAMARERO, Hernán y HERRERA, Carlos, (Comps.), (2005), El Partido Socialista en Argentina. Sociedad, politica e ideas a través de un siglo. Buenos Aires: Prometeo.

DE PRIVITELLIO, Luciano, (2011), «Las elecciones entre dos reformas, 1900-1955,» en SABATO, Hilda, TERNAVASIO, Marcela, DE PRIVITELLIO, Luciano y. PERSELLO, Ana Virginia, Historia de las elecciones en la Argentina, 1805-2011. Buenos Aires: El Ateneo.

FRITZSCHE, Peter, (1990), «Presidential Victory and Popular Festivi-

${ }^{41} L V, 03 / 03 / 1916$, p. 2. 
ty in Weimar Germany: Hindenburg's 1925 Election», Central European History, Vol. 23, 2-3, June: 205-24.

GARGUIN, Enrique, (1999), «La marea roja. El triunfo socialista en las elecciones porteñas de 1913», Socio-histórica, n. 6: 147-181.

GENE Marcela y Juan BUONOME, (2013), «Consumidores virtuosos. Las imágenes publicitarias en el diseño gráfico de La Vanguardia (1913-1930), en Laura MALOSETTI COSTA y M. GENE, Atrapados por la imagen. Arte y politica en la cultura impresa argentina. Buenos Aires: Edhasa.

HOROWITZ, Joel, (2015), El Radicalismo y el movimiento popular (19161930). Buenos Aires: Edhasa.

KARUSH, Matthew, (2002), Workers or Citizens. Democracy and Identity in Rosario, Argentina (1912-1930), Albuquerque: University of New Mexico Press.

LAWRENCE, Jon, (2006), «The transformation of British Public Politics After the First World War», Past \& Present, 190.1: 185-216.

LAWRENCE, Jon, (2009), Electing Our Masters. The Huntings in British Politics from Hogarth to Blair. Oxford: Oxford University Press.

MARTINEZ MAZZOLA, Ricardo, (2015), «Males pasajeros? El Partido Socialista frente a las consecuencias de la Ley Sáenz Peña». En: Archivos de historia del movimiento obrero y la izquierda, Año III, n. 6: 53-72.

PERSELLO, Ana Virginia, (2004), El Partido Radical. Gobierno y oposición, 1916-1943. Buenos Aires: Siglo XXI.

PORTANTIERO, Juan Carlos, (1999), Juan B. Justo. Buenos Aires: FCE.

POY, Lucas, (2015), «El Partido Socialista y las huelgas: una relación incomoda. Un análisis de las posiciones partidarias en los prime-

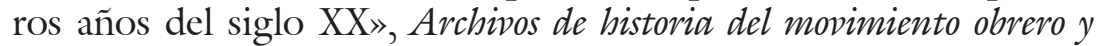
la izquierda, Año IIII, n. 6: 31-52.

REINOSO, Roberto (comp.), (1985), La Vanguardia: Selección de Textos (1894-1955).Buenos Aires: CEAL.

SABATO, Hilda, (1998), La politica en las calles entre el voto y la movilización. Buenos Aires, 1862-1880. Buenos Aires: Sudamericana.

THOMPSON, James, (2007), «'Pictorial Lies'? Posters and Politics in Britain, c. 1880-1914», Past \& Present, 197. 1: 177-210. 
TORRE, Juan Carlos, (1973), «La primera victoria electoral socialista», Todo es Historia, N. 76: 42-51.

VALDEZ, María José, (2012), «El Plebiscito de Hipólito Yrigoyen: La campaña electoral de 1928 en la ciudad de Buenos Aires vista desde La Época», Población y Sociedad, Vol. 19, n. 1: 75-103.

WALKER, Richard, (1977), The Socialist Party of Argentina, 1890-1930. Austin Texas: The University of Texas Press. 